\title{
EI citoesqueleto celular en la glándula mamaria y su aplicación diagnóstica
}

\author{
Martínez Pérez JM. ${ }^{1}$, Martínez Rodríguez JM. ${ }^{2}$
}

Sanid. mil. 2011; 67 (2): 92-97; ISSN: 1887-8571

\begin{abstract}
RESUMEN
Objetivos: Valorar la importancia de las modificaciones que aparecen en el citoesqueleto celular (en particular a nivel de unos filamentos intermedios denominados queratinas) a lo largo de los cambios que sufre la glándula mamaria, con especial referencia a la lactación. Su expresión será diferente y servirá como método de contraste. Diseño: 40 ratones distribuidos en cinco grupos según la etapa de estudio. El esquema experimental es común para todos ellos. Material y métodos: Análisis inmunohistoquímico de las muestras procedentes de las glándulas mamarias para evidenciar modificaciones a nivel de las citoqueratinas y comparación con otros estudios en diferentes modelos animales. Resultados: Cada citoqueratina presenta una expresión diferente según sea la estirpe celular y el periodo de lactación. Se diferencian mediante el uso de anticuerpos específicos marcados. Conclusiones: La expresión citoqueratínica varía de manera fisiológica y en células tumorales. La detección inmunohistoquímica de citoqueratinas puede servir como método de diagnóstico complementario.
\end{abstract}

PALABRAS CLAVE: Citoesqueleto, filamentos intermedios, citoqueratina, mama, cáncer.

\section{The cellular cytoskeleton in the mammary gland and its diagnostic application} SUMMARY:

Objectives: To assess the importance of the changes that appear into the cytoskeleton (especially referred to some specific intermediate filaments called keratins) through different stages the mammary gland bears, focusing on the lactation. Their expression will be different in pathological conditions and this will be useful for contrasting other procedures. Design: 40 mice distributed into five groups according to the stage of study. The experimental project is the same for everyone. Material and methods: Immunohistochemical analysis from samples obtained from mammary glands in order to show changes into cytokeratin expression and comparison with other researches in different animal models. Results: The expression of every cytokeratin is different according to the cell lineage and the lactation period. Specific antibodies can reveal it. Conclusions: The cytokeratinic pattern changes in a physiological sense and also in malignant processes. Immunohistochemical detection of cytokeratins may be useful as complementary diagnosis.

KEYWORDS: Cytoskeleton, intermediate filaments, cytokeratin, mammary gland, cancer.

\section{INTRODUCCIÓN}

El cáncer de mama es el más frecuente en la población femenina española con una tasa de incidencia de 40-75 casos por cada 100.000 mujeres. Es la primera causa de muerte por tumores en mujeres en España y la segunda en EEUU tras el cáncer de pulmón ${ }^{1}$. El $75 \%$ de los casos aparece en mujeres de más de cincuenta años. Es el responsable de casi el $30 \%$ de fallecimientos por causa de cáncer, aunque esta cifra tiende a disminuir gracias a su detección precoz y a los nuevos tratamientos. En el caso de varones supone menos del 1\% de todos los casos de cáncer de mama, con un $0,1 \%$ de mortalidad ${ }^{2}$.

Estudios recientes sugieren la importancia del tratamiento sobre la propia detección y retrasan la edad de inicio de los chequeos a cincuenta años ${ }^{3}$. La valoración diagnóstica debe ser multidisciplinar, incluyendo una exploración física ${ }^{4}$ y mamografías; y si fuera

${ }^{1}$ Licenciado en Veterinaria. CSIC-Universidad de León. Departamento de Sanidad Anima (Parasitología y Enfermedades Parasitarias). Instituto de Ganadería de Montaña. España. ${ }^{2}$ Doctor en Veterinaria. Profesor Titular. Universidad de León. Facultad de Veterinaria. España.

Dirección para correspondencia: José Manuel Martínez Rodríguez. Facultad de Veterinaria de León. Departamento de Medicina, Cirugía y Anatomía Veterinaria (Historia de la Veterinaria). Campus de Vegazana s/n. 24071 León. Correo electrónico: jmmarr@unileon.es

Recibido: 28 de junio de 2010

Aceptado: 15 de diciembre de 2010 necesario biopsias, estereotaxia, análisis de marcadores tumorales ${ }^{5}$, etc. Algunos autores desaconsejan la realización de estudios genéticos de detección por su baja especificidad ${ }^{6}$ a la par que otros los defienden ${ }^{7}$. Los tratamientos varían según el individuo, el tipo y estirpe de cáncer mamario y su expansión. Tumores histológicamente similares se pueden comportar de modo distinto, por ello el pronóstico y el tratamiento son difíciles de establecer ${ }^{4}$.

La comparación de la casuística del cáncer de mama en humanos y en el ratón de laboratorio se explica porque éste es un modelo ideal por su parecido morfofisiológico glandular y en su frecuencia de aparición de tumores mamarios espontáneos similar a la humana. A partir del perfil de expresión de los filamentos intermedios (en especial del patrón citoqueratínico) se pueden establecer analogías y diferencias entre tejidos sanos y neoplásicos, y además servir como primera etapa para categorizar el fenotipo tumoral. En una segunda etapa podría avanzarse en el análisis mediante técnicas de Biología Molecular e identificar los genes implicados ${ }^{8}$. Se considera que todos los cánceres tienen un origen genético en su nivel celular por una acumulación de alteraciones y mutaciones en los genes, que produce inestabilidad genómica y una pérdida del control sobre el crecimiento, desarrollo y diferenciación de la célula. Se necesitan entre tres y seis alteraciones en genes reguladores para que tenga lugar una tumoración ${ }^{2}$. Varios tipos de genes pueden ser los afectados, principalmente los genes supresores y los genes reparadores. Un fallo en los primeros condiciona un crecimiento sin 


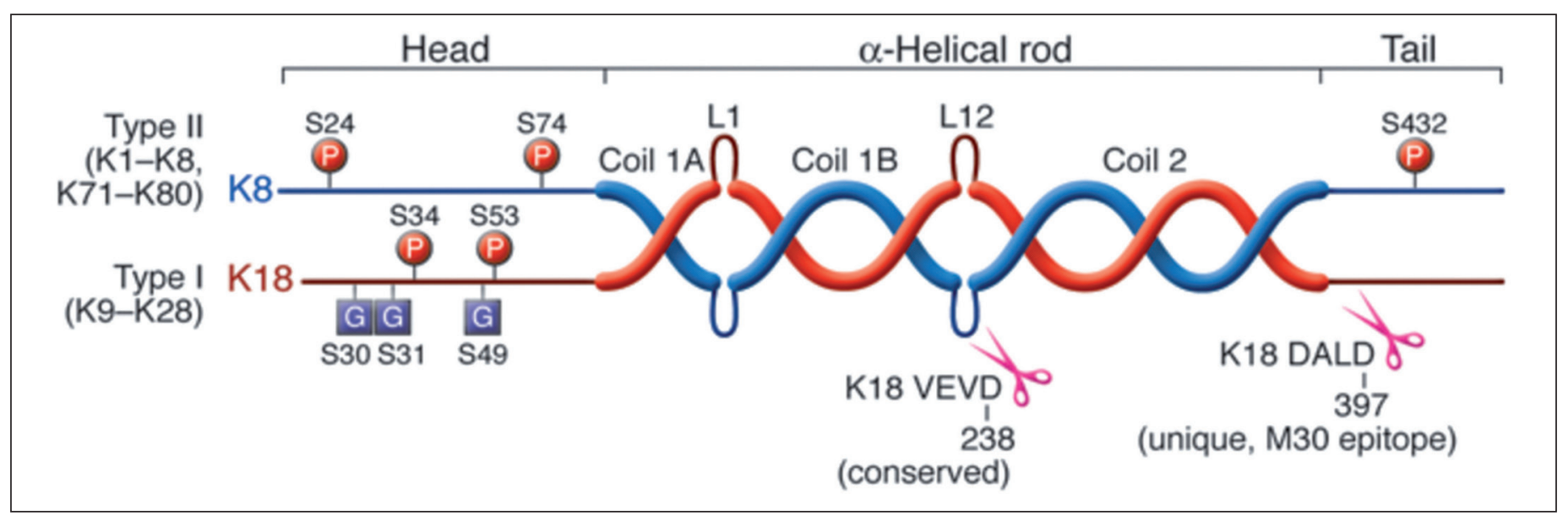

Figura 1. Estructura de las queratinas de tipos $I$ y $I I^{15}$.

control de una estirpe celular; una alteración en los segundos ocasiona una amplificación de los errores del código genético. En este trabajo se muestran los resultados experimentales de los cambios que se producen en la glándula mamaria de ratona (principalmente durante la lactación) y que se acompañan de alteraciones en la expresión del patrón citoqueratínico.

La célula eucariota tiene sus proteínas estructuradas en forma de esqueleto celular. El citoesqueleto está constituido por tres tipos de elementos: los microtúbulos, los microfilamentos y los filamentos intermedios. Estos últimos se caracterizan por ser los elementos citoesqueléticos más resistentes ${ }^{9}$. Su función es proporcionar resistencia mecánica a la célula e interaccionar con otros componentes del citoesqueleto, así como regular la localización de proteínas y la transmisión de señales intracelulares ${ }^{10}$. Su expresión tiene lugar en localizaciones específicas dentro del compartimento celular ${ }^{11}$. En relación con su situación podemos hablar de neurofilamentos (en las neuronas y en los axones de los sistemas nerviosos central y periférico), gliofilamentos (en el citoplasma de los astrocitos y de algunas células asociadas a éstos) ${ }^{12}$, citoqueratinas (en células epiteliales), filamentos de desmina (en los músculos liso y estriado), filamentos de vimentina (en células mesenquimáticas, células epiteliales, células de Schwann y células de la glía), filamentos de periferina (en las neuronas de los ganglios raquídeos, simpáticos y parasimpáticos, las neuronas sensoriales y las motoras del asta anterior de la médula espinal y de algunos núcleos motores de los nervios craneales) y láminas nucleares (dispuestas en forma de red en una gran variedad de tipos celulares $)^{9}$.

El subgrupo más amplio dentro del conjunto de filamentos intermedios lo constituyen las citoqueratinas. Están presentes en células epiteliales; cada tipo epitelial presenta un patrón ${ }^{13,14}$

La asociación entre las diferentes proteínas da lugar a heteropolímeros obligados no covalentes que incluyen al menos una queratina del grupo I (ácida) y otra del grupo II (básica) ${ }^{16}$, pero dicha unión no es al azar, las combinaciones están determinadas: las citoqueratinas 1 y 2 se asocian con la 10, la 5 con la 14 , la 6 con la 16 y la 17 , la 8 se une a la 18. (Figura 1). Están formadas por numerosas clases de proteínas fibrilares, ácidas o básicas, con un diámetro de $8 \mathrm{~nm}$. Su función principal es proteger a las células epiteliales del estrés mecánico ${ }^{17}$. Los componentes de la familia citoqueratínica son más de sesenta. Se puede subdividir en seis categorías según la homología de secuencia, estructura génica y propiedades de ensamblaje; la quinta categoría tiene sus propias particularidades ${ }^{18}$. Los tipos I-IV incluyen filamentos intermedios citoplásmicos, mientras que el tipo $\mathrm{V}$ genera filamentos nucleares.

La composición de subunidades de citoqueratinas es extremadamente heterogénea, variando con dependencia de la localización anatómica, el crecimiento celular, el ambiente, el estado de diferenciación y el momento de desarrollo embrionario. La expresión de citoqueratinas en numerosos epitelios es diferente en tejidos normales si la comparamos con los tejidos tumorales, lo que es un criterio diagnóstico efectivo con el uso de los anticuerpos anti-citoqueratina apropiados ${ }^{19,20}$. De hecho en la epidermis se sintetizan las citoqueratinas 1 y la 10, en la córnea la 3 y la $12^{21}$, en el esófago la 4 y la 13, en la epidermis palmo-plantar la 9, y la 6 en los brotes terminales. El endotelio corneal, formado por una capa única de células planas hexagonales, también expresa el complejo $8 / 18^{22}$. Las queratinas expresadas principalmente en epitelios simples son llamadas SEK's (Queratinas de Epitelios Simples) y aquí se engloban la 7, 8, 18, $19,20,23$ y $24^{23}$. Concretamente en la glándula mamaria podemos encontrar distintas SEK's dependiendo de si el tejido es normal o está alterado (Tabla I). Regiones de epidermis especializada muestran por tanto distintos patrones de diferenciación celular y expresan citoqueratinas específicas ${ }^{24}$. La principal función de las SEK's es servir como protectores celulares evitando en cierta medida la apoptosis y proporcionando una integridad mecánica fundamental ${ }^{25,26}$. Su existencia está relacionada con la localización y la función de orgánulos celulares; la rotura de éstos (como el aparato de Golgi o las mitocondrias) ${ }^{27}$ se vincula con la apoptosis y es un factor crítico en desórdenes patogénicos. Las queratinas (en especial las SEK's) inducen cambios en la apoptosis, modulan la síntesis proteica ${ }^{28}$, contribuyen a la polaridad epitelial y regulan las interacciones con un incremento de la selección de proteínas asociadas.

La generación de ratones transgénicos y silenciados para las SEK's («SEK knockout») ${ }^{29}$ son esenciales para obtener información de la función citoqueratínica in vivo y son muy útiles para la identificación de enfermedades relacionadas con mutaciones en los genes

Tabla 1. Localización de las SEK's en tejido mamario

\begin{tabular}{|lcccccccccc|}
\hline & \multicolumn{1}{c|}{ DISTRIBUCIÓN DE SEK's } \\
\cline { 2 - 7 } TEJIDO NORMAL & $\mathrm{X}$ & 5 & $\mathrm{X}$ & 7 & 8 & 14 & 15 & 17 & 18 & 19 \\
TEJIDO NEOPLÁSICO & 4 & 5 & 6 & 7 & 8 & 14 & $\mathrm{X}$ & 17 & 18 & 19 \\
\hline
\end{tabular}


Tabla 2. Expresión de citoqueratinas en diferentes etapas de estudio

\begin{tabular}{|lccccc|}
\hline \multirow{2}{*}{ Anticuerpos / Citoqueratinas } & \multicolumn{5}{c|}{ SEMANAS POSTPARTO } \\
\cline { 2 - 6 } & $1 .^{\mathrm{a}}$ & $2^{\mathrm{a}}{ }^{\mathrm{a}}$ & $3 .^{\mathrm{a}}$ & $4 .^{\mathrm{a}}$ & $5 .^{\mathrm{a}}$ \\
\hline Anti-CK1 (CK1) & - & - & - & - & - \\
Anti-CK5 (CK5) & ++ & ++ & ++ & ++ & ++ \\
LLO20 y Anti-CK6 (CK6) & - & - & - & - & + \\
LP1K (CK7) & + & + & + & + & + \\
TROMA1 (CK8) & - & ++ & ++ & ++ & ++ \\
Anti-CK13 (CK13) & - & - & - & - & - \\
LLOO1 y Anti-CK14 (CK14) & + & + & + & + & - \\
LLO25 (CK16) & $+/-$ & - & $+/-$ & - & + \\
LP2K (CK19) & $+/-$ & - & - & - & $+/-$ \\
\hline
\end{tabular}

(-) no tinción; (+) tinción positiva en $10-50 \%$ de las células; $(++)$ tinción positiva en más del $50 \%$ de las células; $(+/-)$ resultado variable en el análisis.

que codifican para las mismas, siendo diferentes los cambios si los comparamos en otras queratinas.

Debido a su gran diversidad estructural, en número y su expresión específica tisular, las citoqueratinas sirven como marcadores histológicos tumorales importantes y tienen una gran significación durante la embriogénesi ${ }^{30} \mathrm{y}$ en condiciones de estrés: en la embriogénesis la expresión de las citoqueratinas de tipo II precede a las de tipo I, aunque los componentes de ambas familias se requieren para formar los filamentos intermedios; las condiciones de estrés afectan en mayor medida, no sólo en cuanto al perfil o patrón de expresión citoqueratínico, sino también al nivel expresivo e inducen cambios posteriores en el ensamblaje.

\section{MATERIAL Y MÉTODOS}

\section{Diseño experimental}

- Animales de experimentación: El animal de estudio es el ratón NMRI (Naval Medical Research Institute) ${ }^{31}$, idóneo por su prolificidad y adaptabilidad a diferentes ambientes. Se utilizaron cuarenta hembras gestantes (ocho por cada periodo de estudio). Estuvieron controladas con ciclos de iluminación-oscuridad de 24 horas a $23{ }^{\circ} \mathrm{C}$. La comida y la bebida no fueron restringidas; de media ingirieron 5 gramos de pienso y 5 mililitros de agua al día. El alojamiento no presentaba un área inferior a $180 \mathrm{~cm}^{2}$, con una altura mínima en la jaula de $12 \mathrm{~cm}$. Los sacrificios se realizaron mediante desnucamiento cervical; los animales eran pesados y se procedía a la necropsia reglada recogiendo todos los órganos del animal. Se dividió el proceso en cinco semanas según la etapa.

- Procedimientos inmunohistoquímicos: Las glándulas mamarias eran extirpadas y congeladas en nitrógeno líquido. Las secciones de tejido fueron cortadas con el criostato a $5 \mu \mathrm{m}$ de espesor. La fijación se llevó a cabo en formol tamponado al 10\% durante 24 horas. Fueron incluidos en parafina y seccionados a $4 \mu \mathrm{m}$. Las secciones se fijaron con hematoxilina y eosina.

- Anticuerpos Mono y Policlonales Anti-Queratina: La expresión de los subtipos de queratina fue evaluada mediante seis anticuerpos diferentes en secciones congeladas usando inmunofluorescencia indirecta. Se utilizaron antisueros procedentes de ratón, conejo y rata. El de rata se unió con FITC (Fluorocromo Isotiocianato de
Fluoresceína) y los de ratón y conejo reaccionaron con el Texas Red. Las secciones teñidas se catalogaron como resultado negativo (-), tinción heterogénea en el $10-50 \%$ de las células $(+)$, tinción intensa en más del $50 \%$ de las células $(++)$ y resultado variable (+/-). El desarrollo de la glándula mamaria de ratón ha sido analizado inmunohistoquímicamente usando anticuerpos monoclonales para células de superficie y proteínas de la membrana basal, así como un anticuerpo policlonal antiqueratínico, identificando cuatro tipos celulares básicos: basal, alveolar secretor, tubular luminal y mioepitelial ${ }^{32}$.

\section{Técnicas utilizadas}

- Inmunofluorescencia indirecta (IFI): Mediante esta técnica de elevada sensibilidad, los anticuerpos específicos no marcados se unen en una primera etapa al antígeno para, en un segundo paso, incorporarse el anticuerpo marcado con el fluorocromo. El antisuero no se marca, sino que se emplea con un fluorocromo en una etapa posterior. De este modo los anticuerpos deben reconocer las citoqueratinas $1,5,6,7,8,13,14,16$ y 19 .

- Doble Inmunofluorescencia Indirecta (dIFI): La doble inmunofluorescencia está ideada por la incubación secuencial de anticuerpos primarios y FITC -o Texas Red- conjugados con anticuerpos secundarios. Su finalidad fue reconocer las citoqueratinas 5,6 y 8 .

\section{Técnica fotográfica}

El material utilizado consistió en un microscopio «Diaplan» (Leitz) equipado con un sistema de epifluorescencia que reconocía ambos fluorocromos. Las microfotografías se tomaron con una cámara «Wild MPS» $51 \mathrm{~S}$ con película «Kodakcolor VR» de 400S para inmunofluorescencia.

\section{RESULTADOS}

El objetivo experimental fue el análisis del patrón de expresión citoqueratínico en glándulas mamarias de ratona durante las cinco etapas de estudio (cuatro de ellas durante la lactación). Se presentan los resultados para las diferentes citoqueratinas dependiendo de la etapa de estudio.

El patrón de expresión para la citoqueratina 5 (Figuras 2 y 3) es similar en glándulas funcionales y no funcionales en la primera semana

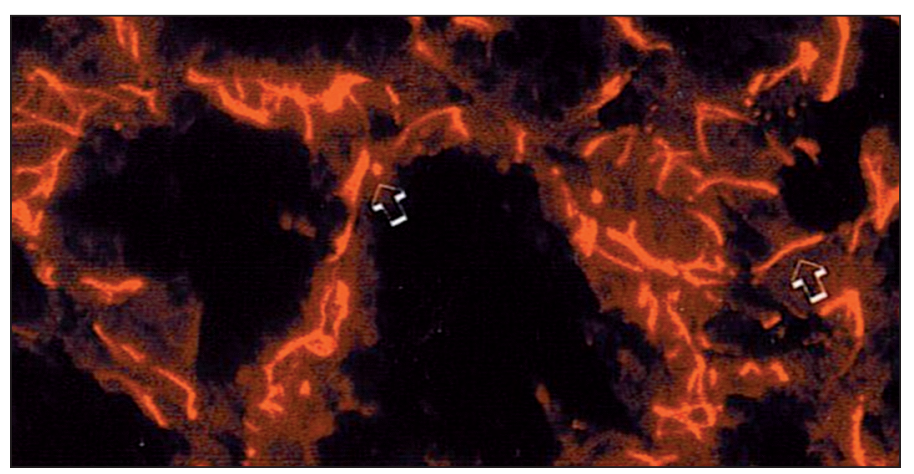

Figura 2. Expresión de la citoqueratina 5 en glándula mamaria de ratón durante la $3 .{ }^{a}$ semana de lactación. Tinción de las células mioepiteliales $(\Longrightarrow)$. 


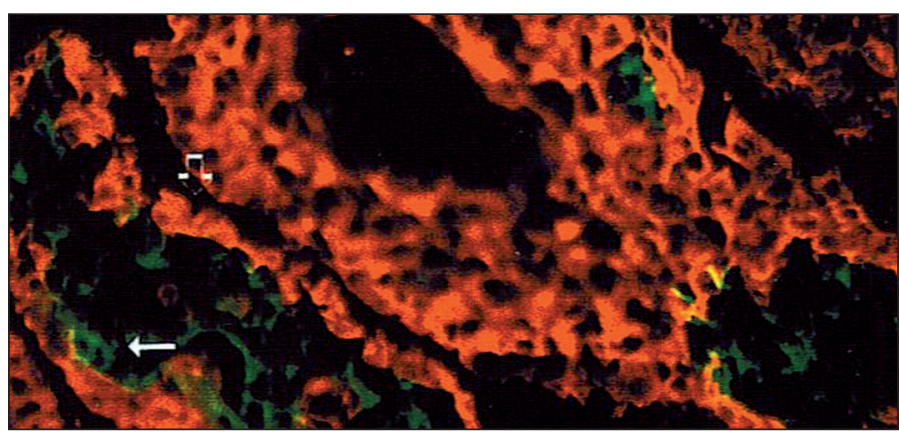

Figura 3. Expresión de las citoqueratinas 5 -rojo- $(\Longrightarrow)$ y 8 -verde- $(\longrightarrow)$ en un alveolo durante la $3 .^{a}$ semana en lactación.

en lactación. La mayoría de las tinciones se encontraron en las células mioepiteliales y basales, mientras que las células de los conductos secretores y las alveolares fueron claramente negativas. Las células mioepiteliales reaccionaron con intensidad al anti-CK5 durante la etapa en lactación, pudiendo observarse las proyecciones citoplásmicas características de este tipo celular rodeando al alveolo mamario.

En cuanto a la citoqueratina 8 (Figura 3) se observó una clara respuesta en células secretoras alveolares y en las que revisten los conductos, durante la segunda, tercera y cuarta semana en lactación. En tejidos mamarios obtenidos durante la quinta etapa hubo una intensa reactividad en células de la luz de los conductos. No se detectó en células de tejidos procedentes de glándulas mamarias en la primera semana de lactación, lo que implica que la existencia de cambios morfológicos en el inicio de la lactación puede originar modificaciones en el citoesqueleto celular llevando, en este caso, a un solapamiento de esta citoqueratina, característica de epitelios simples glandulares.

En algunos casos la citoqueratina 7 (Figura 4) se detectó en tejidos de glándulas mamarias en lactación; las células positivas eran tanto las que revisten los conductos excretores como las alveolares. Con respecto a las glándulas de la quinta semana, se encontraron respuestas positivas aisladas en el alveolo. Paralelamente al curso de las fases se apreció un incremento en el número de células positivas a la citoqueratina 7 , detectándose en las células de los conductos excretores.

Las citoqueratinas 6 y 16 fueron identificadas con una fluorescencia débil en las células mamarias en reposo. Para la citoqueratina 16 (Figura 5), algunas células resultaron positivas durante la primera y tercera semanas en lactación. Estas citoqueratinas son características de células suprabasales y de queratinocitos en proliferación, y han sido encontradas también en algunos epitelios estratificados.

Respecto a la citoqueratina 14 (Figura 6), los anticuerpos anti-CK14 produjeron una reacción moderada en células acinares y ductales. La capa basal de las células epiteliales de los conductos resultó ser negativa en los cuatro periodos en lactación en todas las muestras analizadas. Al igual que ocurre con la citoqueratina 5, la citoqueratina 14 es expresada en células mioepiteliales.

Los resultados obtenidos con LP2K (específico para la citoqueratina 19) fueron difusos y sólo unas pocas células luminales tubulares dieron positivo en alguno de los individuos.

Las citoqueratinas 1 y 13 resultaron negativas en todas las fases del estudio.

Si analizamos nuestros resultados, en especial los relativos a las citoqueratinas 7 y 8 , se puede asegurar que las alteraciones produci-

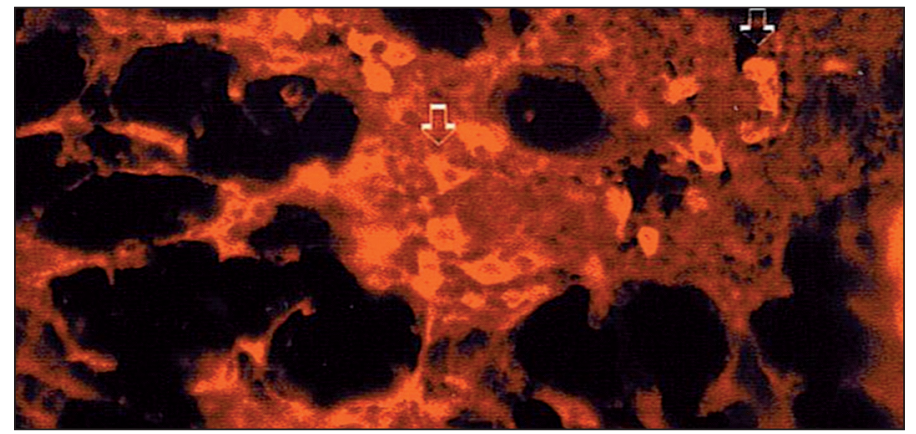

Figura 4. Expresión de la citoqueratina 7 en una pequeña cantidad de células de la glándula mamaria en el periodo lactante $(\Longrightarrow)$.

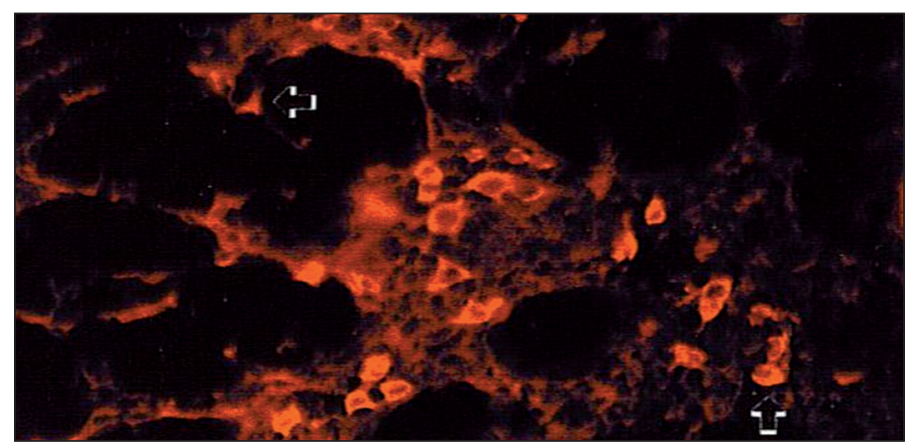

Figura 5. Expresión de la citoqueratina 16 en células aisladas de una glándula mamaria en lactación $(\Longrightarrow)$.

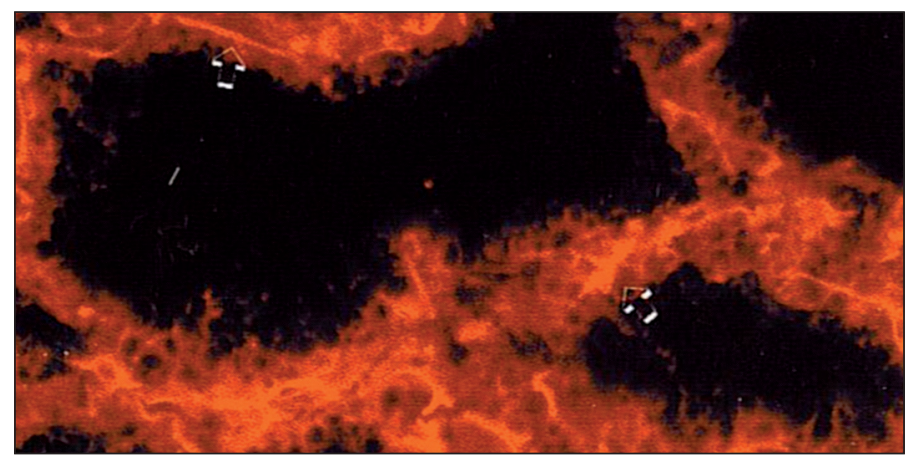

Figura 6. Expresión de la citoqueratina 14 en glándula mamaria durante la $1^{a}$ semana de lactación. Tinción de las células mioepiteliales que rodean al alveolo mamario $(\Longrightarrow)$.

das en el citoesqueleto celular, no detectables en un estudio histológico convencional, se pueden evidenciar mediante un procedimiento inmunohistoquímico, sin obviar otras variables como el momento funcional glandular.

\section{DISCUSIÓN}

La caracterización inmunofenotípica de la tipología celular en la glándula mamaria provee información en cuanto a los procesos de diferenciación, la dinámica e interacción celular y el efecto de las hormonas en el desarrollo de la propia glándula ${ }^{6,33}$. La interpretación de los resultados indica que el compartimento de la luz de los conductos está compuesto por una gran variabilidad celular, la diferenciación se logra mediante cambios evidentes en la colora- 
ción con los elementos empleados, el grado de marcaje de casi todas las citoqueratinas del estudio depende de la fase de desarrollo de la glándula mamaria y la naturaleza de las citoqueratinas expresadas en células de la luz y basales está conservada a través de todo el árbol mamario ${ }^{34,35}$, aunque los niveles de expresión dependen de su localización específica. La cantidad de marcadores de diferenciación expresados por las células de la luz de los conductos y las basales $^{36}$ fue incrementando paulatinamente durante la morfogénesis mamaria.

Las células mioepiteliales de la ratona durante la pubertad y posteriormente pueden diferenciarse de las células de la luz de los conductos ya que expresarían la citoqueratina 5. Los resultados obtenidos muestran que esta proteína es expresada en células mioepiteliales y basales de los conductos. Esto también se refleja en otros estudios de ratón, rata, felinos y humanos ${ }^{13,37}$. No debemos olvidar que las citoqueratinas 5 y 14 se suelen encontrar en la capa basal de la epidermis y en anejos organizándose formando una pareja en forma de grandes filamentos ${ }^{17}$.

La citoqueratina 8 apareció uniformemente distribuida en la glándula mamaria durante todas las etapas de estudio excepto la primera semana. Las células positivas a la reacción fueron las alveolares y las de la luz de los conductos. Esto contrasta con resultados publicados anteriormente donde la expresión de esta citoqueratina ha sido detectada en ratones y ratas $^{32}$. Las razones de esta discrepancia pueden deberse a la técnica empleada. Podría ser que en la primera semana de lactación, durante los cambios fisiológicos controlados por el estado hormonal, hubiera alteraciones en la estructura celular que supusieran una inaccesibilidad de esta proteína al anticuerpo utilizado en este estudio. Es típica de epitelios simples. Igualmente ocurre en el caso de humana ${ }^{38}$. Asimismo unas pocas células suprabasales podrían parecer positivas a la reacción, pero no de una forma clara, lo que se debe a su localización y tamaño, así como su diferenciación según la etapa de estudio ${ }^{39}$. El complejo de citoqueratinas $8 / 18$ es considerado un marcador específico de células de la luz de los conductos y de epitelios simples de humana, algo que puede diferir si lo comparamos con un estudio en ratones, debido principalmente a los anticuerpos que reconocen proteínas diferentes. El patrón de expresión de las citoqueratinas 8 y 18 puede ser actualmente monitorizado mediante ingeniería transgénica en ratones a partir de una proteína verde fluorescente bajo el control del promotor de una de dichas citoqueratinas ${ }^{40}$; éste es un hecho fundamental para el avance en el estudio de estos filamentos ${ }^{22}$.

La citoqueratina 7 fue positiva en todas las etapas de estudio. Un incremento en su positividad se observó a medida que la lactación progresaba, hasta completarse en todas las células de los conductos mamarios. Esto significa que aunque no se encuentren diferencias a nivel histológico sí existen cambios en el citoesqueleto celular que pueden ser debidos a la distinta capacidad funcional celular, según la variabilidad del patrón citoesquelético. Es un marcador importante de diferenciación ductal, expresándose en carcinomas mamarios. Junto con la queratina 20 es muy útil en el diagnóstico de cánceres de difícil detección por estar poco diferenciados ${ }^{34}$.

La citoqueratina 6 está confinada a una pequeña cantidad de células epiteliales mamarias asociadas con el crecimiento de los brotes terminales y del epitelio de la luz de los $\operatorname{conductos}^{41,42}$. Esta citoqueratina no fue detectada en ninguna etapa del desarrollo de la glándula mamaria en el experimento de Mikaelian ${ }^{35}$, contrastando con las observaciones efectuadas por Smith ${ }^{41}$, que la identificó mediante in- munofluorescencia en brotes terminales y en algunas células de los conductos intralobulares, y que indujo a otros a considerarla como marcador de células pluripotentes mamarias ${ }^{43}$. Los resultados obtenidos para las citoqueratinas 6 y 16 se restringieron a algunas células en reposo, así como a un pequeño número de células catalogadas como positivas durante la primera y tercera semana en lactación.

Las células mioepiteliales expresaron la citoqueratina 14; no se detectó en las células basales de los conductos en ninguna de las etapas. Estos resultados concuerdan con otros anteriores ${ }^{44}$.

Los resultados obtenidos para la citoqueratina 19 no fueron claros con el anticuerpo utilizado. Esto coincide con estudios efectuados en glándula mamaria de humana por investigadores anteriores, aunque éstos sí obtuvieron resultados claramente positivos para la citoqueratina 19 en células alveolares y de la luz de los conductos ${ }^{45}$. Se puede deber a que el anticuerpo empleado no fuera el adecuado y diera falsos resultados. La positividad se mostró en algunas células dispersas de la luz de los conductos durante la primera semana y la quinta.

La citoqueratina 13 no se expresa en la glándula mamaria de ratona, en cambio sí se ha identificado en el caso de humana. Algo parecido ocurre con las citoqueratinas 1 y 10 , sólo expresadas en procesos carcinogenéticos ${ }^{46}$.

\section{CONCLUSIONES}

- La expresión de las citoqueratinas varía con los cambios fisiológicos celulares y en células tumorales. Existen particularidades en la expresión de dichas proteínas entre las distintas células de un mismo individuo, evidenciadas mediante el uso de la técnica de inmunofluorescencia con los anticuerpos específicos para cada citoqueratina.

- La comparación entre diferentes especies indica ciertas similitudes en el patrón de expresión de las citoqueratinas. Esto pone de manifiesto la validez del diseño experimental planteado.

- Consideramos que la detección inmunohistoquímica de alteraciones a nivel citoesquelético puede servir como método diagnóstico complementario de tumores de naturaleza epitelial.

\section{BIBLIOGRAFÍA}

1. Berg JW, Hutter RV. Breast cancer. Cancer 1995; 75: 257-269.

2. Lorenzo N, Domínguez A, García MV. Características del cáncer de mama masculino en hospitales públicos de la Comunidad Autónoma de Madrid. Sanidad Militar 2010; 66(2):97-101.

3. Jorgensen KJ, Zahl PH, Gotzsche PC. Breast cancer mortality in organised mammography screening in Denmark: comparative study. British Medical Journal 2010; 340: c1241.

4. Galán JA, Castro J, Tabanera A, Martí L. Reactividad inmunohistoquímica frente a los antígenos humanos p53, c-erbB-2, Ki-67 y ER de los tumores mamarios de la perra. Sanidad Militar (Rev. Sanidad de las FFAA de España) 2007; 63(3): $182-191$.

5. Gómez de Terreros FJ, Álvarez-Sala MC, Prados M, Callol L, Gómez FJ, Sánchez J. Cómo expresar los marcadores tumorales en el lavado broncoalveolar. Med. Mil. 2003; 59(1): 22-25.

6. Teng D, Bogden R, Mitchell J, Baumgard M, Bell R, Barry S et al. Low incidence of BRCA2 mutations in breast carcinoma and other cancers. Nature Genetics 1996; 13: 241-244.

7. Beckmann MW, Picard F, An HX, Van Roeyen CR, Dominik SI, Mosny DS et al. Clinical impact of detection of loss of heterozygosity of BRCA1 and BRCA2 markers in sporadic breast cancer. British Journal of Cancer 1996; 73(10): 1220-1226. 


\section{El citoesqueleto celular en la glándula mamaria y su aplicación diagnóstica}

8. Mínguez O, Martínez JM. Análisis histopatológico y molecular de los tumores mamarios de ratón provocados por DMBA. Efecto sobre el H-Ras y el BRCA1. Actas VIII Reunión de la Sociedad Española de Anatomía Patológica Veterinaria. Córdoba: 1996.

9. Martínez JM, Martínez JM. Revisión sobre filamentos intermedios, con especial referencia a las citoqueratinas. Revista Complutense de Ciencias Veterinarias 2010; 4(2): 1-11.

10. Paramio JM, Jorcano JL. Beyond structure: do intermediate filaments modulate cell signaling?. BioEssays 2002; 24(9): 836-844.

11. Carrillo N, Ortuño D, Gudiño G. Expresión de las isoformas $\alpha$ y $\beta$ del mRNA del GFAP durante la diferenciación del PNM de BO de rata adulta hacia el fenotipo de aldainoglía y en glía envolvente purificada. Avances en la Investigación Científica en el CUCBA, 2006; 267-273.

12. Eng LF, Ghirnikar RS, Lee YL. Glial fibrillary acidic protein: GFAP-thirty-one years (1969-2000). Neurochemical Research 2000; 25(9-10): 1439-1451.

13. Moll R, Franke WW, Schiller DL. The catalog of human cytokeratins: patterns of expression in normal epithelia, tumors and cultured cells. Cell 1982; 31: 11-24.

14. Aquino CG, Jurado F. Citoqueratinas en dermatología. Revista Mejicana de Dermatología 2008; 52(6): 254-262.

15. Omary M, Ku N, Strnad P, Hanada S. Toward unraveling the complexity of simple epithelial keratins in human disease. The Journal of Clinical Investigation 2009; 119(7): 1794-1805

16. Coulombe PA, Omary MB. 'Hard' and 'soft' principles defining the structure, function and regulation of keratin IF. Current Opinion in Cell Biology 2002; 14: 110-122.

17. Lee $\mathrm{CH}$, Coulombe PA. Self-organization of keratin intermediate filaments into crosslinked networks. The Journal of Cell Biology 2009; 186(3): 409-421.

18. Strelkov SV, Herrmann H, Geisler N, Wedig T, Zimbelmann N, Aebi U et al. Conserved segments $1 \mathrm{~A}$ and $2 \mathrm{~B}$ of the intermediate filament dimmer: their atomic structures and role in filament assembly. The EMBO Journal 2002; 21: 1255-1266

19. Pellegrino MB, Asch BB, Connolly JL, Asch HL. Differential expression of keratins 13 and 16 in normal epithelium, benign lesions, and ductal carcinomas of the human breast determined by the monoclonal antibody Ks8.12. Cancer Research 1988; 48: 5831-5836

20. Bennett CN, Green JE. Genomic analyses as a guide to target identification and preclinical testing of mouse models of breast cancer. Toxicologic Pathology 2010 38: 88-95.

21. Nithya J, Tilak P, Vidya P, Anil P, Sreenivasan K, Kumary T. A cytocompatible poly (N-isopropylacrylamide-coglycidylmethacrylate) coated surface as new substrate for corneal tissue engineering. Journal of Bioactive and Compatible Polymers 2010; 52: 58-74.

22. Jirsova K, Merjava S, Martincova R, Gwilliam R, Ebenezer ND, Liskova P et al. Immunohistochemical characterization of cytokeratins in the abnormal corneal endothelium of posterior polymorphous corneal dystrophy patients. Exp. Eye Research 2007; 84(4): 680-686.

23. Rogers MA, Winter H, Langbein L, Bleiler R, Schweizer J. The human type I keratin gene family: characterization of new hair follicle specific members and evaluation of the chromosome 17q21.2 gene domain. Differentiation 2004; 72(910): $527-540$.

24. Eastwood J, Offutt C, Menon K, Keel M, Hrncirova P, Novotny MV et al. Identification of markers for nipple epidermis: changes in expression during pregnancy and lactation. Differentiation 2007; 75(1): 75-83.

25. Marceau N, Schutte B, Gilbert S, Loranger A, Henfling M, Broers J et al. Dua roles of intermediate filaments in apoptosis. Experimental Cell Research 2007 313(10): 2265-2281.

26. Wagner OI, Rammensee S, Korde N, Wen Q, Leterrier JF, Janmey PA. Softness, strength and self-repair in IF networks. Experimental Cell Research 2007; 313(10): 2228-2235.
27. Gonatas NK, Stieber A, Gonatas JO. Fragmentation of the Golgi apparatus in neurodegenerative diseases and cell death. Journal Neurological Sciences 2006; 246(1-2): 21-30.

28. Kim S, Wong P, Coulombe PA. A keratin cytoskeletal protein regulates protein synthesis and epithelial cell growth. Nature 2006; 441: 362-365.

29. Magin TM. Lessons from keratin transgenic and KO mice. Sub. Biochem. 1998; 31: 141-172.

30. Lu H, Hesse M, Peters B, Magin TM. Type II keratins precede type I during early embryonic development. European Journal of Cell Biology 2005; 84(8): 709-718.

31. Bravo AM, Martínez JM, García MJ, Escudero A. Inducción de tumores de intestino grueso en ratón NMRI tras la administración de DMH. Medicina Veterinaria 1992; 9(10): 590-602.

32. Lichtner RB, Julian JA, North SM, Glasser SR, Nicolson GL. Coexpression of cytokeratins characteristic for myoepithelial and luminal cell lineages in rat $13762 \mathrm{NF}$ mammary adenocarcinoma tumors and their spontaneous metastases. Cancer Res. 1991; 51: 5943-5950.

33. Fernández SV, Russo J. Estrogen and xenoestrogens in breast cancer. Toxicologic Pathology 2010; 38(1): 110-122.

34. Mínguez O. Caracterización de los tumores espontáneos y provocados por DMBA en la mama de ratón. León: Servicio de Publicaciones de la Universidad de León, 1998: 13-20, 42-46.

35. Mikaelian I, Hovick M, Silva KA, Burzenski LM, Shultz LD, Ackert-Bicknell $\mathrm{CL}$ et al. Expression of terminal differentiation proteins defines stages of mouse mammary gland development. Veterinary Pathology 2006; 43(1): 36-49.

36. Painter JT, Clayton NP, Herbert RA. Useful immunohistochemical markers of tumor differentiation. Toxicologic Pathology 2010; 38(1): 131-141.

37. Ivanyi D, Minke JM, Hageman C, Groeneveld E, Van Doornewaard G. Patterns of expression of feline cytokeratins in healthy epithelia and mammary carcinoma cells. American Journal of Veterinary Research 1992; 53(3): 304-314.

38. Michalczyk A, Brown RW, Collins JP, Ackland ML. Lactation affects expression of intermediate filaments in human breast epithelium. Differentiation 2001; 67(12): 41-49.

39. Ersahin C, Chivukula M, Bhargava R, Dabbs DJ. Basal-like subtype breast cancers in women older than 40 years of age. International Journal of Surgical Pathology 2010; 18(1): 42-47.

40. Renou JP, Bierie B, Miyoshi K, Cui Y, Djiane J, Reichenstein M et al. Identification of genes differentially expressed in mouse mammary epithelium transformed by an activated beta-catenin. Oncogene 2003; 22(29): 4594-4610.

41. Smith GH, Mehrel T, Roop DR. Differential keratin gene expression in developing differentiating, preneoplastic and neoplastic mouse mammary epithelium. Cell Growth \& Differentiation 1990; 1(4): 161-170.

42. Zhang RR, Man YG, Vang R, Saenger JS, Barner R, Wheeler DT et al. A subset of morphologically distinct mammary myoepithelial cells lack corresponding immunophenotypic markers. Breast Cancer Research 2003; 5(5): R151-R156.

43. Welm B, Behbod F, Goodell MA, Rosen JM. Isolation and characterization of functional mammary gland stem cells. Cell Proliferation 2003; 36(1): 17-32.

44. Bässler R, Katzer B. Histopathology of myoepithelial (basocellular) hyperplasias in adenosis and epitheliosis of the breast demonstrated by the reactivity of cytokeratins and S100 protein. Virchows Archive A: Pathological Anatomy and Histopathology 1992; 421: 435-442.

45. Su L, Morgan PR, Lane EB. Expression of cytokeratin messenger RNA Vs. protein in the normal mammary gland and in breast cancer. Human Pathology 1996; 27(8): 800-806.

46. HogenEsch H, Boggess D, Sundberg JP. Changes in keratin and filaggrin expression in the skin of chronic proliferative dermatitis (cpdm) mutant mice. Pathobiology 1999; 67(1): 45-50. 